\title{
Migration behaviour of Europium implanted into single crystalline $6 \mathrm{H}-\mathrm{SiC}$
}

T.M. Mohlala ${ }^{1}$, T.T. Hlatshwayo ${ }^{1 *}$, M. Mlambo ${ }^{1}$, E.G. Njoroge ${ }^{1}$, S.V. Motloung ${ }^{2}$, J.B. Malherbe $^{1}$

\author{
${ }^{1}$ Department of Physics, University of Pretoria, Lynnwood Road, Pretoria 0002, South Africa \\ ${ }^{2}$ Department of Physics, Sefako Makgatho Health Science University, P. O. Box 94, Medunsa, 0204, South \\ Africa \\ *Corresponding author: thulani.hlatshwayo@up.ac.za
}

\section{Highlights}

- Eu ions were implanted into $6 \mathrm{H}-\mathrm{SiC}$ at $600{ }^{\circ} \mathrm{C}$.

- Annealing studies were performed at temperatures ranging from 1000 to $1400{ }^{\circ} \mathrm{C}$.

- The migration of Eu together with annealing of radiation damage were performed.

- The migration of Eu was explained in terms of trapping and de-trapping by radiation damage.

\begin{abstract}
Migration behaviour of Europium (Eu) implanted into $6 \mathrm{H}-\mathrm{SiC}$ was investigated using Rutherford backscattering spectroscopy (RBS), RBS in a channelling mode (RBS-C) and scanning electron microscopy (SEM). Eu ions of $360 \mathrm{keV}$ were implanted into $6 \mathrm{H}-\mathrm{SiC}$ at 600 ${ }^{\circ} \mathrm{C}$ to a fluence of $1 \times 10^{16} \mathrm{~cm}^{-2}$. The implanted samples were sequentially annealed at temperatures ranging from 1000 to $1400{ }^{\circ} \mathrm{C}$, in steps of $100{ }^{\circ} \mathrm{C}$ for 5 hours. RBS-C showed that implantation of Eu into $6 \mathrm{H}-\mathrm{SiC}$ at $600{ }^{\circ} \mathrm{C}$ retained crystallinity with some radiation damage. Annealing of radiation damage retained after implantation already took place after annealing at $1000{ }^{\circ} \mathrm{C}$. This annealing of radiation damage progressed with increasing annealing temperature up to $1400{ }^{\circ} \mathrm{C}$. A shift of Eu towards the surface took place after annealing at $1000{ }^{\circ} \mathrm{C}$. This shift became more pronounced and was accompanied by loss of $\mathrm{Eu}$ from the surface at annealing temperatures $>1000{ }^{\circ} \mathrm{C}$. This shift was accompanied by
\end{abstract}


broadening of Eu peak /Fickian diffusion after annealing at temperatures $>1100{ }^{\circ} \mathrm{C}$. The migration of Eu occurring concurrently with the annealing of radiation damage was explained by trapping and de-trapping of Eu by radiation damage.

Keywords: RBS, RBS-C, SiC, Radiation damage, diffusion

\section{Introduction}

The containment of fission products (FPs) is critical in the design of the nuclear reactors [1]. In Generation IV nuclear reactors, fuel kernels $\left(\mathrm{UO}_{2}\right)$ are coated by four successive layers [2]. These layers are graphite buffer, inner pyrocarbon (PyC), silicon carbide (SiC) and an outer pyrocarbon. The main function of the low density PyC layer, (the buffer layer) is to attenuate fission recoils and to provide voids for gaseous FPs and carbon monoxides that are produced. The inner PyC retains gaseous FPs. The SiC layer retains solid fission products or acts as barrier to solids fission products and provides adequate structural stability during fuel compact fabrication. The outer high-density PyC protects SiC layer mechanically. This coated particle is known as tri-isotropic (TRISO) particle.

TRISO particles retain most of the FPs well with the exception of silver (Ag), strontium ( $\mathrm{Sr}$ ) and Europium (Eu) during operation [2,3]. Generation IV Reactor program includes high temperature reactors (HTR's), operating at temperatures well above $1000{ }^{\circ} \mathrm{C}$ to enhance their efficiency, especially in view of process heat applications for hydrogen generation [4]. Extensive investigations have been performed in the migration behaviour of $\mathrm{Ag}$ in $\mathrm{SiC}$ in the temperatures below and above $1000{ }^{\circ} \mathrm{C}$ [5]. Very little has been reported on the migration behaviour of $\mathrm{Eu}$ in $\mathrm{SiC}[1,6]$. Europium is a highly reactive metal which react with $\mathrm{Si}$ to form a stable silicide and with carbon to form a stable carbide. Consequently, one would expect that at high temperatures (like those used in this study) and at the concentration levels used in this study (i.e. a maximum 2 atomic percent) that Eu would dissolve in the $\mathrm{SiC}$. Eu is toxic to lungs and mucous membrane if inhaled, it is corrosive and an irritant to skin [7]. In the reported studies of the migration behaviour of $\mathrm{Eu}$ in $\mathrm{SiC}$, the influence of radiation damage has not been investigated. In the nuclear reactor environment, $\mathrm{SiC}$ is continuously exposed to irradiation, hence the influence of radiation damage in the migration of Eu in $\mathrm{SiC}$ is crucial. 
In this study we report, on the investigation of influence of radiation damage in the migration behaviour of Eu implanted into $6 \mathrm{H}-\mathrm{SiC}$ to a fluence of $1 \times 10^{16} \mathrm{~cm}^{-2}$. The radiation damage retained after implantation played a major role in the migration behaviour of implanted Eu.

\section{Experimental method}

Single crystalline $6 \mathrm{H}-\mathrm{SiC}$ wafers from Valley design Corporation were used in this study. Implantation was performed with $360 \mathrm{KeV}$ Eu ions at $600{ }^{\circ} \mathrm{C}$ to a fluence of $1 \times 10^{16} \mathrm{~cm}^{-2}$. To avoid channelling, implantation was done at an angle of $7^{\circ}$ relative to normal incidence. The implanted wafers were isochronal annealed in vacuum using a computer controlled Webb 77 graphite furnace at temperatures ranging from 1000 to $1400{ }^{\circ} \mathrm{C}$, in steps of $100{ }^{\circ} \mathrm{C}$ for 5 hours. Eu distribution before and after annealing was monitored by Rutherford backscattering spectroscopy(RBS) at room temperature by the production of a collimated beam of $\mathrm{He}^{+}$ particles with energy $1.4 \mathrm{MeV}$ at a scattering angle of $165^{\circ}$. The same set-up was also used to investigate radiation damage in the single crystalline samples by Rutherford backscattering spectroscopy in a channelling mode spectroscopy (RBS-C). The backscattered energy in channels were converted into depth (in $\mathrm{nm}$ ) using the energy loss data and the density of pristine $\mathrm{SiC}$ i.e. $3.21 \mathrm{gcm}^{-3}$. Samples surfaces before and after annealing were investigated by field emission scanning electron microscopy (FEG-SEM) employing a Zeiss Ultra 55 instrument fitted with the usual SEM detectors and an in-lens detector.

\section{Results}

RBS spectra (both Random and aligned) of Eu implanted $6 \mathrm{H}-\mathrm{SiC}$ at $600{ }^{\circ} \mathrm{C}$ are shown in Fig. 1. The un-implanted $6 \mathrm{H}-\mathrm{SiC}$ (virgin) spectrum is included for comparison. Arrows in Fig. 1 indicate the surface energy positions in channels of the elements. Implantation at 600 ${ }^{\circ} \mathrm{C}$ resulted in the appearance of the broad peak around channel 230. This peak indicates the amount of radiation damage retained after implantation. The radiation damage peak in Fig. 1 does not overlap the random spectrum, indicting the absence of amorphous material. The lack of amorphization is due to the availability of thermal energy to the displaced atoms that increase the probability of recombination. Similar results have been reported for other implanted FPs surrogates at the same implantation temperature [8-14].

The measured Eu depth profile (from RBS), the TRIM simulated Eu depth profile and displacement per atom( $(d p a)$ are shown in Fig.2. The projected range of measured Eu depth 
profile is in reasonable agreement with TRIM simulation, while the as-implanted profile is broader than the simulated due to TRIM approximations. The major dpa are closer to the surface as compare to the implanted Eu profile.

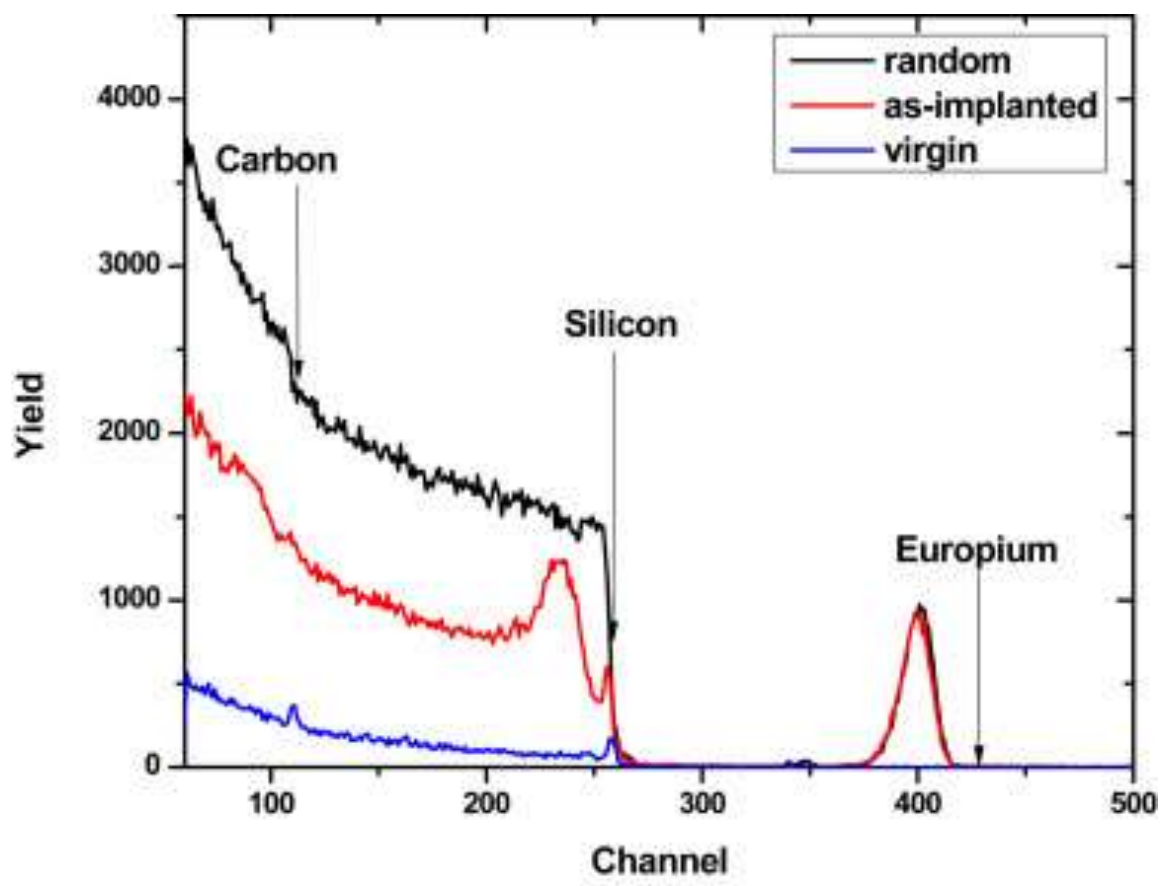

Fig. 1: RBS spectra of $6 \mathrm{H}$-SiC implanted with $270 \mathrm{KeV}$ Eu ions (both Random and aligned) at $600{ }^{\circ} \mathrm{C}$ and the virgin spectra is included.

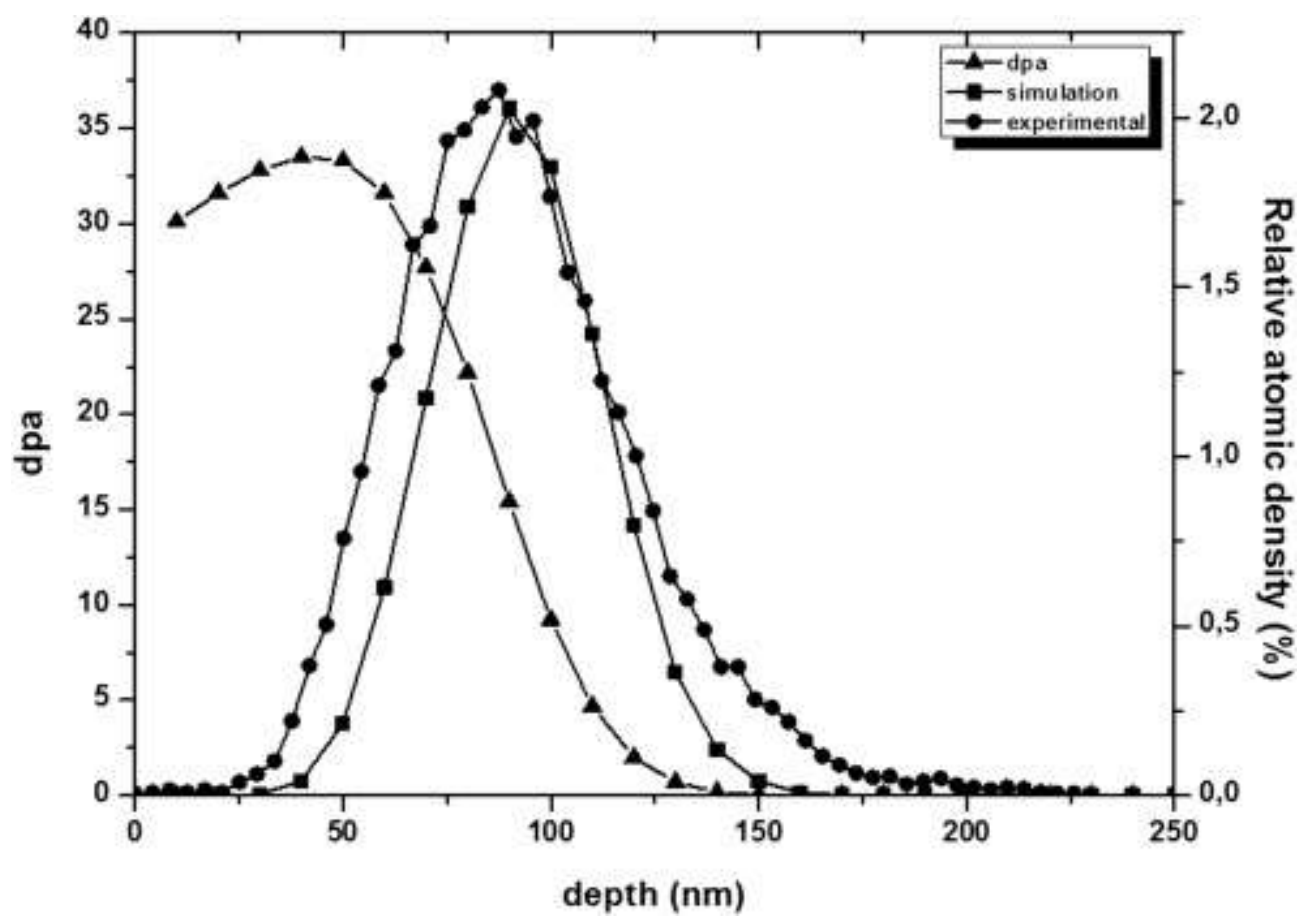

Fig. 2: The as-implanted Eu(360 keV) depth profile(from RBS),TRIM simulated Eu depth profile and displacement per atom(dpa). 
The aligned silicon depth profiles of the implanted $6 \mathrm{H}-\mathrm{SiC}$ after isochronal annealing at 1000, 1100, 1200, 1300 and $1400{ }^{\circ} \mathrm{C}$ are shown in Fig. 3 (the random, virgin and as implanted spectra are included for comparison). Annealing at $1000^{\circ} \mathrm{C}$ caused some reduction in the radiation damage peak, indicating some annealing of radiation damage at this temperature. This reduction of radiation damage was more pronounced at $1100{ }^{\circ} \mathrm{C}$, indicating further annealing. The radiation damage peak was further reduced after annealing at $1200{ }^{\circ} \mathrm{C}$ indicating a continued annealing of radiation damage. The peak completely disappeared after annealing at 1300 and $1400{ }^{\circ} \mathrm{C}$. Even though the reduction of radiation damage within the lattice is significant after annealing at $1400{ }^{\circ} \mathrm{C}$, it is still high compared to the un-implanted (virgin) sample, indicating that the total annealing of radiation damage was not achieved at these temperatures.

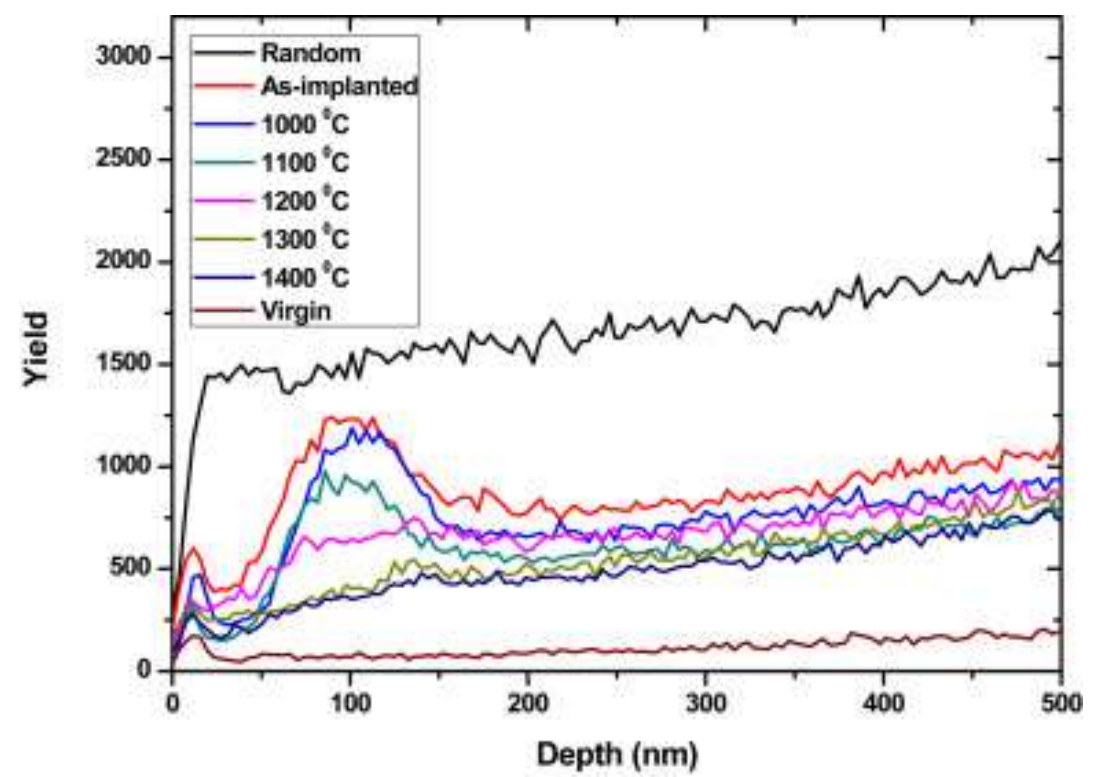

Fig. 3: Si depth profile of Eu implanted into SiC by $270 \mathrm{KeV} \mathrm{Eu} \mathrm{ions} \mathrm{and} \mathrm{annealed} \mathrm{at} \mathrm{various} \mathrm{temperatures.}$

The migration of $\mathrm{Eu}$ implanted into $6 \mathrm{H}-\mathrm{SiC}$ was investigated simultaneously with the annealing of radiation damage. The Eu depth profiles obtained from RBS after isochronal annealing are shown in Fig. 4 (the as-implanted profile is included for comparison). Comparing the radiation damage results in Fig. 3 with the Eu depth profiles, the as-implanted is initially embedded in radiation damage region. Annealing at $1000{ }^{\circ} \mathrm{C}$ resulted to a shift of Eu peak towards the surface, indicating the migration of Eu towards the surface is already taking place (see Fig.5. (c)). This migration towards the surface became more significant with increasing annealing temperature. 


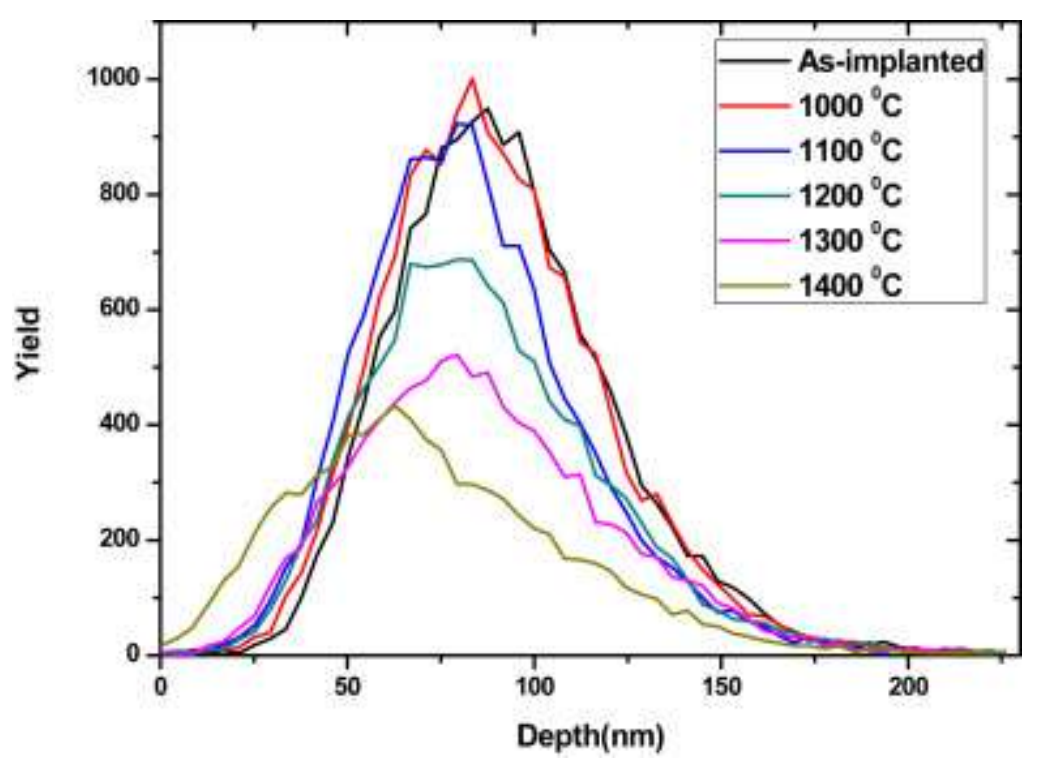

Fig. 4: Eu depth profiles of Eu implanted into $6 \mathrm{H}$-SiC at $600{ }^{\circ} \mathrm{C}$ after isochronal annealing at various temperatures for 5 hours.

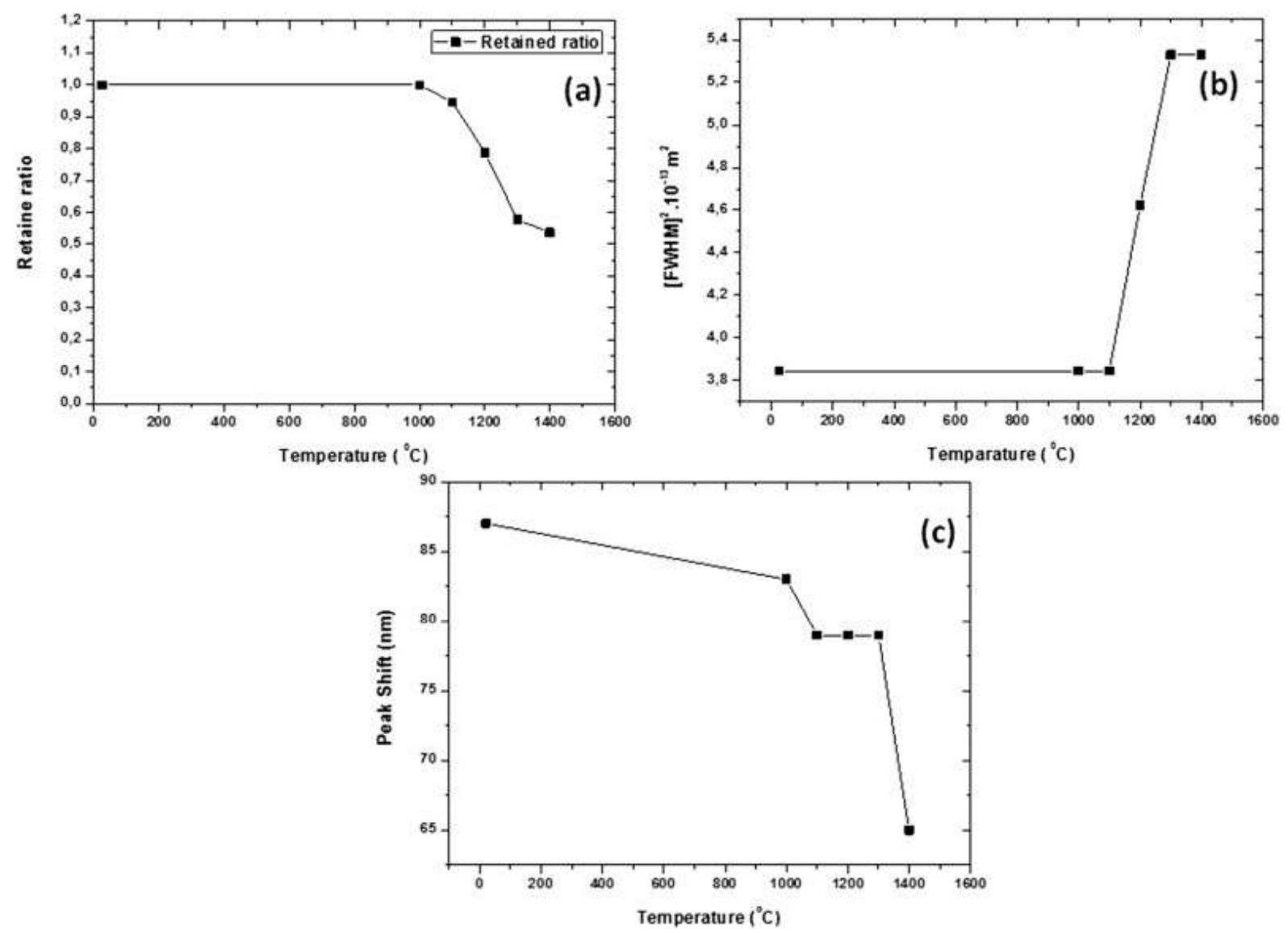

Fig. 5:(a) Retained ratio of Eu implanted into $6 \mathrm{H}$-SiC at $600{ }^{\circ} \mathrm{C}$ after isochronal annealing at different temperatures for 5 hours (b) Full width at half maximum plotted as a function of temperature for $270 \mathrm{KeV}$ of $\mathrm{Eu}$ ions in $6 \mathrm{H}$-SiC implanted at $600{ }^{\circ} \mathrm{C}$ after isochronal annealing at different temperatures for 5 hours and (c) Peak shift of the Eu profile of as-implanted and annealed at 1000 to $1400{ }^{\circ} \mathrm{C}$ in steps of $100{ }^{\circ} \mathrm{C}$. 
The retained ratios were calculated as the ratio of the area of Eu counts after annealing to that of as-implanted and the results are illustrated in-Fig. 5 (a). The retained ratio reveals that the migration of Eu towards the surface was accompanied by a subsequent loss from the surface at annealing temperatures above $1000{ }^{\circ} \mathrm{C}$. About $10 \%$ of Eu is lost after annealing at $1100{ }^{\circ} \mathrm{C}$ and about $50 \%$ was lost after annealing at 1300 and $1400{ }^{\circ} \mathrm{C}$.

The diffusion of implanted Eu was investigated by comparing the full width at half maximum (FWHM) of the Eu depth profiles of the as-implanted and the annealed samples. The FWHMs square is plotted as a function of temperature in Fig. 5 (b). The FWHM obtained after annealing at 1000 to $1100{ }^{\circ} \mathrm{C}$, showed no broadening indicating no detectable Fickian diffusion after annealing at these temperatures, however the Eu peak shifted towards the surface as observed in Fig. 5 (c). The broadening of the FWHM was observed after annealing at 1200 and $1300{ }^{\circ} \mathrm{C}$ indicating the beginning of Fickian diffusion at these temperatures. Annealing at $1400{ }^{\circ} \mathrm{C}$ showed no broadening of the FWHM. No further Eu peak shift (as compare to $1100{ }^{\circ} \mathrm{C}$ ) was observed at 1200 and $1300{ }^{\circ} \mathrm{C}$, indicating that the Eu loss was purely due to Fickian diffusion, while a further shift was observed at $1400{ }^{\circ} \mathrm{C}$

The shift of Eu peak towards the surface combined with annealing of radiation damage, may be due to trapping and de-trapping of Eu implants. On the as-implanted samples Eu is trapped by radiation damage retained after implantation. As these radiation damage are annealed, detrapping of Eu occurs which allows the Eu to shift towards the surface. This process progresses with increasing temperature until the temperature where diffusion take place.

The surface topography of the as-implanted compared with annealed samples are shown in Fig. 6. The as-implanted samples were fairly smooth. No major changes were observed after annealing up to $1200{ }^{\circ} \mathrm{C}$. These results indicate that the shift towards the surface after annealing up until $1100{ }^{\circ} \mathrm{C}$, is not caused by changes in the samples' surface which confirms the trapping and de-trapping of implants theory suggested earlier. Also the SEM images show the deterioration on the surface after annealing at 1300 and $1400{ }^{\circ} \mathrm{C}$. This is due to thermal etching of the material during annealing [15]. However, this thermal etching took place at lower temperatures than the one at which it occurred $\left(1500{ }^{\circ} \mathrm{C}\right)$ [15]. The peak broadening is not observed after annealing at $1400{ }^{\circ} \mathrm{C}$ but the shift and loss of Eu is considerably high. This can be explained by the severe surface changes of the sample after annealing at this temperature. Also more $\mathrm{Eu}$ might have been etched away during thermal etching of the material at these high annealing temperatures. 


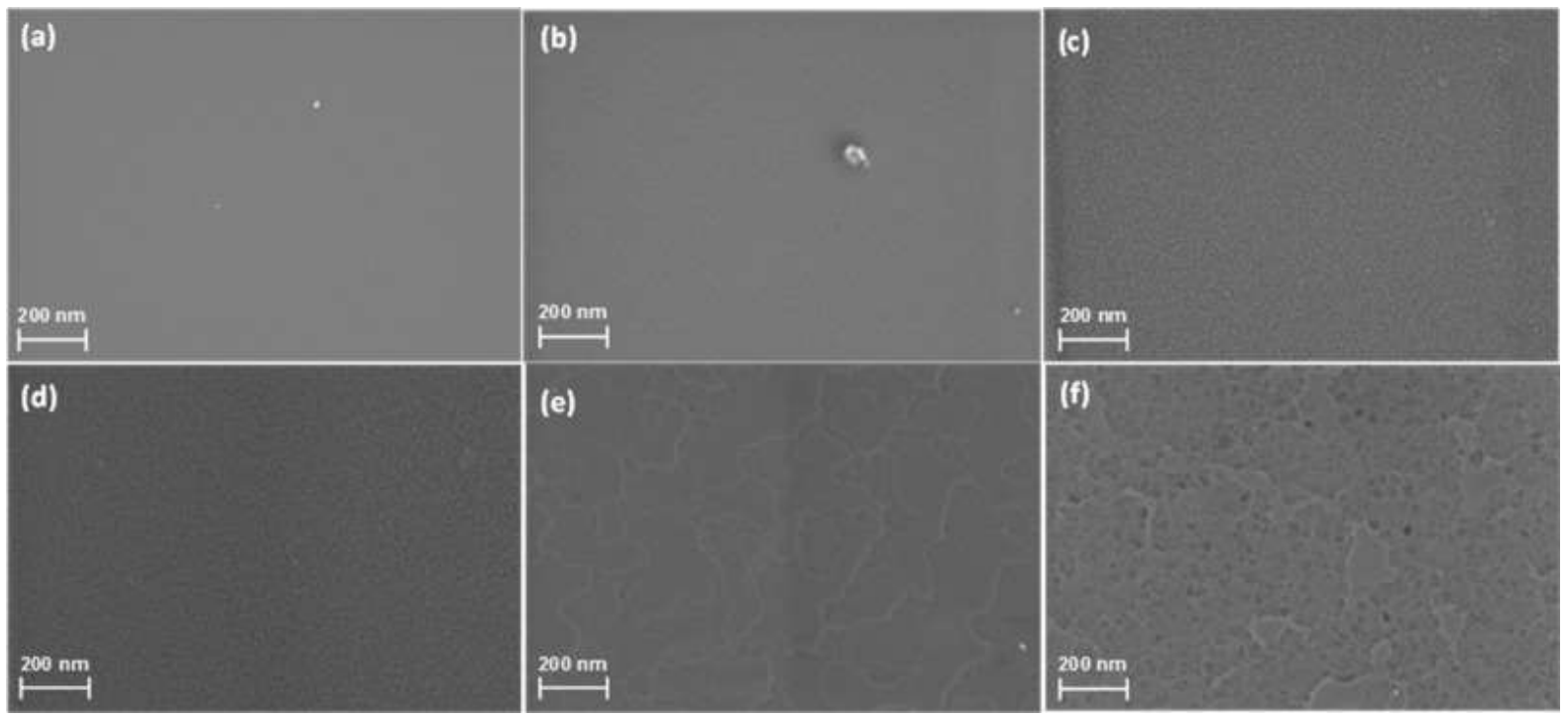

Fig 6: SEM images of Eu ions implanted into $6 \mathrm{H}-\mathrm{SiC}$ at $600^{\circ} \mathrm{C}:$ (a) as-implanted, subsequently annealed at (b) 1000, (c) 1100, (d) 1200, (e)1300 and (f) $1400{ }^{\circ} \mathrm{C}$.

\section{Summary}

This study focused on the migration behaviour of $\mathrm{Eu}$ implanted into $6 \mathrm{H}-\mathrm{SiC}$ at $600{ }^{\circ} \mathrm{C}$. Implantation temperature retained crystallinity of $6 \mathrm{H}-\mathrm{SiC}$ with some defects. This was expected as the implantation temperature was above the critical temperature of $\mathrm{SiC}$ amorphization. Annealing of radiation damage retained after implantation already took place after annealing at $1000{ }^{\circ} \mathrm{C}$. This annealing of radiation damage progressed with increasing annealing temperature up to $1400^{\circ} \mathrm{C}$. The shift of Eu towards the surface was already taking place after annealing at $1000{ }^{\circ} \mathrm{C}$ and became more pronounced with increasing temperature (where it was accompanied by Eu loss from the surface). Fickian's diffusion of Eu was only observed after annealing at $1200{ }^{\circ} \mathrm{C}$ and continued up until $1300{ }^{\circ} \mathrm{C}$. No Fick's diffusion was observed after annealing at $1400{ }^{\circ} \mathrm{C}$. The shift of Eu profiles after annealing from 1000 to $1200{ }^{\circ} \mathrm{C}$ was explained using trapping and de-trapping of the implanted ions by defects. A further shift of Eu at $1400{ }^{\circ} \mathrm{C}$ was due to thermal etching of the surface.

\section{Acknowledgements}

The financial support from the National Research Foundation (NRF) of South Africa is appreciated. 


\section{References}

[1] Dwaraknath, S. and Was, G. (2014). Development of a multi-layer diffusion couple to study fission product transport in $\beta$-SiC. Journal of Nuclear Materials, 444(13), pp.170-174.

[2] Malherbe, J.B., Friedland, E. and van der Berg, N. (2008). Ion beam analysis of materials in the PBMR reactor.Nuclear Instruments and Methods in Physics Research Section B: $\quad$ Beam Interactions with Materials and Atoms, 266(8), pp.1373-1377.

[3] Internation atomic energy agency, (1997). Fuel performance and fission product behaviour in gas cooled reactors. [online] Available at: http://wwwpub.iaea.org/books/IAEABooks/5633/Fuel-Performance-and-FissionProduct

Behaviour-in-Gas-Cooled-Reactors [Accessed 8 Feb. 2017].

[4] Anon,(2016).[online]Availableat:

https://www.hydrogen.energy.gov/pdfs/national_h2_roadmap.pdf [Accessed 10 Jun. 2016].

[5] Malherbe, J.B. (2013). Diffusion of fission products and radiation damage in SiC. Journal of Physics D: Applied Physics, 46(47), p.473001.

[6] Dwaraknath, S. and Was, G. (2016). The diffusion of cesium, strontium, and europium in silicon carbide.Journal of Nuclear Materials, 476, pp.155-167.

[7] Anon, (2016). [online] Available at:

http://www.sciencelab.com/msds.php?msdsId=9924008 [Accessed 10

Jun. 2016].

[8] Friedland, E., Malherbe, J.B, van der Berg, N., Hlatshwayo, T., Botha, A., Wendler, E. and Wesch, W. (2009). Study of silver diffusion in silicon carbide.Journal of Nuclear Materials, 389(2), pp.326-331.

[9] Friedland, E., van der Berg, N., Malherbe, J.B, Kuhudzai, R., Botha, A., Wendler, E.

and Wesch, W. (2010). Study of iodine diffusion in silicon carbide.Nuclear

Instruments and Methods in Physics Research Section B: Beam Interactions with Materials and Atoms, 268(19), pp.2892-2896.

[10] Friedland, E., van der Berg, N., Hlatshwayo, T., Kuhudzai, R., Malherbe, J.B., Wendler, E. anWesch, W. (2012). Diffusion behavior of cesium in silicon carbide at $\mathrm{T}>1000^{\circ}$ C.Nuclear Instruments and Methods in Physics Research Section B:Beam Interactions with Materials and Atoms, 286, pp.102-107.

[11] Malherbe, J.B., van der Berg, N., Botha, A., Friedland, E., Hlatshwayo, T., Kuhudzai, R., Wendler, E., Wesch, W., Chakraborty, P. and da Silveira, E. (2013). SEM analysis of ion implanted SiC.Nuclear Instruments and Methods in Physics Research Section B: $\quad$ Beam Interactions with Materials and Atoms, 315, pp.136-141. 
[12] Friedland, E., Hlatshwayo, T., van der Berg, N. and Mabena, M. (2015). Influence of radiation damage on krypton diffusion in silicon carbide. Nuclear Instruments and Methods in Physics Research Section B: Beam Interactions with Materials and Atoms, 354, pp.42-46.

[13] Friedland, E., van der Berg, N., Hlatshwayo, T., Kuhudzai, R., Malherbe, J.B., Wendler, E. and Wesch, W. (2012). Diffusion behavior of cesium in silicon carbide at $\mathrm{T}>1000^{\circ}$ C.Nuclear Instruments and Methods in Physics Research Section B: Beam Interactions with Materials and Atoms, 286, pp.102-107.

[14] Friedland, E., Hlatshwayo, T. and van der Berg, N. (2013). Influence of radiation damage on diffusion of fission products in silicon carbide. physica status solidi(c), 10(2), pp.208-215.

[15] Hlatshwayo, T., Malherbe, J.B., van der Berg, N., Botha, A. and Chakraborty, P. (2012). Effect of thermal annealing and neutron irradiation in 6H-SiC implanted with silver at $350^{\circ} \mathrm{C}$ and $600^{\circ} \mathrm{C}$. Nuclear Instruments and Methods in Physics Research Section B: $\quad$ Beam Interactions with Materials and Atoms, 273, pp.61-64.

[16] Kachurin, G., Tyschenko, I. and Fedina, L. (1992). High-temperature ion implantation in silicon.Nuclear Instruments and Methods in Physics Research Section B: Beam Interactions with Materials and Atoms, 68(1-4), pp.323330. 